\title{
Holography applications toward medical field: An overview
}

\section{Abid Haleem, Mohd Javaid, Ibrahim Haleem Khan¹}

Department of Mechanical Engineering, Jamia Millia Islamia, 'School of Engineering Sciences and Technology, Jamia Hamdard, New Delhi, India

Correspondence: Dr. Mohd Javaid, Department of Mechanical Engineering, Jamia Millia Islamia, New Delhi - 110025 , India. E-mail:mohdjavaid0786@gmail.com

\begin{abstract}
Purpose: 3D Holography is a commercially available, disruptive innovation, which can be customised as per the requirements and is supporting Industry 4.0. The purpose of this paper is to study the potential applications of 3D holography in the medical field. This paper explores the concept of holography and its significant benefits in the medical field. Methods: The paper is derived through the study of various research papers on Holography and its applications in the medical field. The study tries to identify the direction of research \&development and see how this innovative technology can be used effectively for better treatment of patients. Results: Holography uses digital imaging inputs and provides an extensive visualisation of the data for training doctors, surgeons and students. Holography converts information about the body into a digital format and has the potential to inform, promote and entertain the medical students and doctors. However, it needs a large amount of space for data storage and extensive software support for analysis and skills for customising. This technology seems good to solve a variety of medical issues by storing and using patient data in developing 3D holograms, which are useful to assist successful treatment and surgery. It seems useful in providing flexible solutions in the area of medical research. Finally, the paper identifies 13 significant applications of this technology in the medical field and discusses them appropriately. Conclusion: The paper explores holographic applications in medical research due to its extensive capability of image processing. Holographic images are non-contact 3D images having a large field of depth. A physician can now zoom the holographic image for a better view of the medical part. This innovative technology can create advancements in the diagnosis and treatment process, which can improve medical practice. It helps in quick detection of problems in various organs like brain, heart, liver, kidney etc. By using this technology, medical practitioners can see colourful organs at multiple angles with better accuracy. It opens up an innovative way of planning, testing of procedures and diagnosis. With technological developments, compact hardware and software are now available to help medical research and related applications.
\end{abstract}

Key words: 3D image; applications; detection of disease; holography; imaging; planning; treatment

\section{Introduction}

Holography is an innovative technology that depicts an effective interaction of humans with the digital world. It is a disruptive innovation; where $3 \mathrm{D}$ imaging technologies are used effectively to address challenges in education,

\begin{tabular}{|l|l|}
\hline \multicolumn{2}{|c|}{ Access this article online } \\
\hline Quick Response Code: & Website: \\
\hline & www.ijri.org \\
\cline { 2 - 3 } & DOI: \\
& 10.4103/ijri.IJRI_39_20 \\
\hline
\end{tabular}

training, research, gaming and other associated areas. In the medical field, it can be used for surgical planning, medical diagnostics, radiology and also for obtaining better information about tissues and organs (internal and

This is an open access journal, and articles are distributed under the terms of the Creative Commons Attribution-NonCommercial-ShareAlike 4.0 License, which allows others to remix, tweak, and build upon the work non-commercially, as long as appropriate credit is given and the new creations are licensed under the identical terms.

For reprints contact: WKHLRPMedknow_reprints@wolterskluwer.com

Cite this article as: Haleem A, Javaid M, Khan IH. Holography applications toward medical field: An overview. Indian J Radiol Imaging 2020;30:354-61.

Received: 29-Jan-2020

Accepted: 13-May-2020

Revised: 03-May-2020 Published: $15-$ Oct-2020 
external) when viewed from various angles. It can record high-resolution images of tissues and internal organs. Holography seems to be a good tool to plan an intervention as it opens a new possibility due to its capability of non contact high-resolution imaging and measurement. It provides better information about cavities and deformities in internal organs. It helps physicians during the procedure for the fitting of implants. ${ }^{[1,2]}$

In few industries, holography is used to protect against duplication of the product as it has an excellent capability for the inspection of the product. This technology is available to capture information about vehicles and their number plates. The other applications are in movies, video games etc. Holography is well used for the retail, military and other commercial applications. It assists specific instruction of the patient and eliminates checkup manually. Holography is used for the detailed study of different parts of ear; such as outer ear, middle ear and inner ear under various noisy conditions. It is used for various applications like cornea, tympanic membrane, tooth mobility, basilar membrane, temporal bone, cochlea, incudomalleal joint, skull, chest and bones. ${ }^{[3,4]}$

In cardiology, it is suitable for the therapy of arrhythmias, coronary interventions and heart valve replacements. It provides fast growth to improve healthcare infrastructure ${ }^{[5-7]}$ and endless possibilities in emergency medical care. ${ }^{[8,9]}$

\section{D Holography and its Basic Steps}

In 1948, this technology was coined by Dr Dennis Gabor for which he received the Nobel Prize. The word hologram stands for 'complete message' which means the reconstruction of the image to convey complete message/ information of the given part. Hologram refers to an image that is created when the light reflects upon meeting an object. Thus, it can be seen or obtained with the help of dense air like mist. A hologram is a permanent record of light, which is encapsulated in a three-dimensional object like glass or mirror. Hologram consist of two beams; a reference and an object beam which are diverted with the help of a half mirror and then the light converges forming a hologram using two full mirrors. This technique is used to perform imaging of multidimensional objects. Holography uses hardware, software and more exotic types of programming to create hologram image. This technology records light scattered from an object to present it in a 3D digital image. It allows light to shine through and the image is viewed from one side. The scattering of a laser beam produces multiple light waves that illuminate an object and create an image due to the principle of diffraction. It is recorded through a video camera in a $3 \mathrm{D}$ format. A hologram is a 3D photographic technique which projects image using 3D glasses ${ }^{[1]}$ Hologram diffracts light into an image and is easily projected for planning, teaching, learning and performing of complex surgeries. Figure 1 shows the fundamental physics of 3D holography.

A laser is used to focus the light beam and this beam is further spat. By the spat of the laser beam, an object beam is developed which focusses on the mirror. This action finally provides a hologram of the object. This hologram can also be an image of a patient's body part which can be used successfully in the medical field. The applications of this technology are also increasing in the movie industry.

\section{Steps for using holography in the medical field}

Holography provides better communication for humans due to the extensive capability of 3D visualisation of a patient's body with high resolution. It is used to simplify the procedure of complex treatments. 3D hologram created by this technology is used for clinical applications by the health professionals. Figure 2 shows the major steps for developing 3D holograms for clinical applications in the medical field.

The first step is to install the required hardware and software for the preparation of the required medical image. This prepared image is then projected, by which one can see, a 3D hologram. This hologram is visualised by the doctors and surgeons for proper planning of the treatment which is applied for clinical applications and provides various benefits in the medical field.

\section{Need for the Study}

Holography is an innovative imaging technology which creates detailed imaging that can be used for different applications. In medical imaging, there is a requirement of imaging of internal and external human body parts. There are digital imaging technologies which provide 2 dimensional and even 3D images of body parts. Thus, we

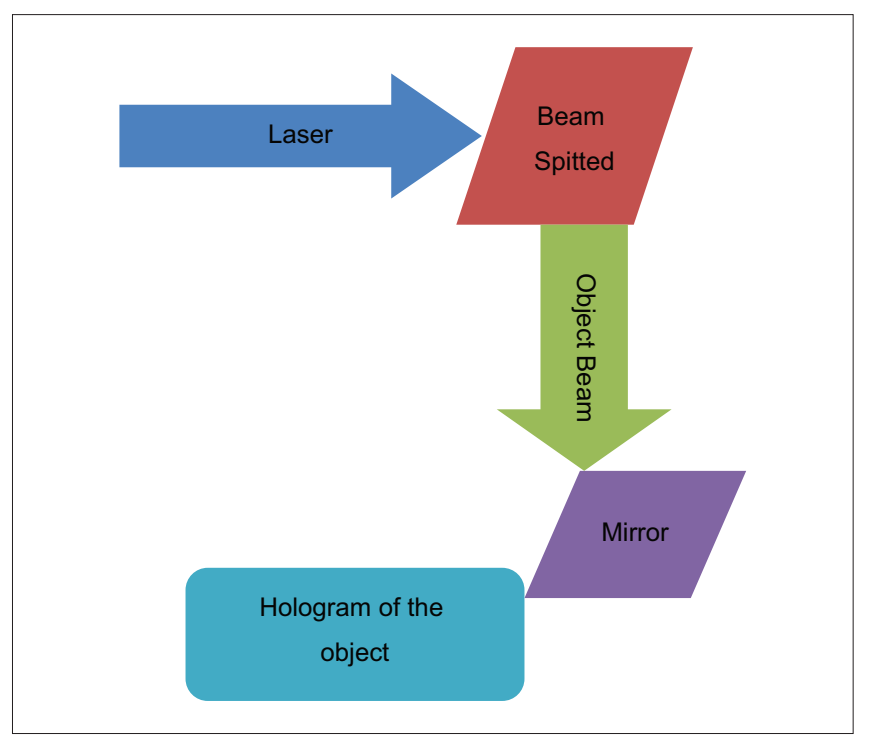

Figure 1: Basic physics of 3D holography 


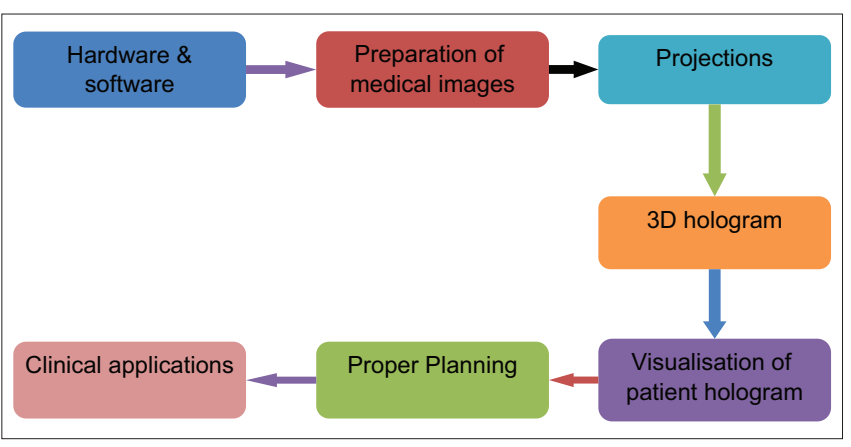

Figure 2:Steps used by holography in the medical field

need to go a step further to see these images in motions, with different scales, with different colours and with languages. Its applications are increasing in image processing and precisely measuring human body parts.

Literature gives us a good idea of the applications of holography used to measure the stress on surgical tools during surgery. It allows examining the different body parts like liver, brain, skeleton, heart, lungs, nerves, vascular system and muscles. It can digitally store patient data and provide a massive amount of detailed information. ${ }^{[10,11]}$ Thus, it is suitable for medical training, tumor localisation and remote therapy, visualisation and complex 3D structure measurement of the human body. In the medical field, holography is used to measure the natural cavity, organs and tissue of the human body in a non-destructive manner. This $3 \mathrm{D}$ visualising technology provides a unique experience to the doctor and offers empowerment to clinicians. It efficiently performs the studies of bones in a contactless manner..$^{[12,13]}$

The need is to understand holography, its basic functioning and identify its significant benefits in using it in the field of medicine. Further, we need to understand the benefits it can deliver to the practitioners. This will help readers to be aware of what is now technologically feasible and may help in changing the perception about the latest developments. Secondly, this will help researchers and doctors in developing future applications.

\section{Benefits of Holography}

This technology is rapidly growing in the medical field for its use in practical studies and explanation. The enormous potential of holography is to import and use high-capacity data. It stores information about multiple images at different angles. ${ }^{[1,12]}$ Different benefits of holography in the medical field are as under:

- Improve the way of procedure and treatment

- Provide advanced imaging

- Effective learning

- Useful for multiple images

- Capacity of storing
- Do not require any projection screen

- Save cost in processes

- Improve customer care

- Increase the efficiency of doctors and surgeons

- 3D visualisation of products and situations

- Do not require special glasses to view

- Store preserve and archive information

Thus, holography provides advancements in education, planning, security, safety and research and development.

\section{Holography for Radiologists}

Holography is an advanced imaging technique that helps radiologists to identify injury or any other fracture in the soft or hard tissue of patients. It improves the safety and better treatment of the patients. With the help of this innovative imaging technique, all previous medical records of the patient can be stored digitally, by which a radiologist can easily examine the medical history of a patient. It has several applications in radiology like cardiovascular, chest, genitourinary, musculoskeletal, neuroradiology, paediatric and head and neck radiology. Holography has excellent capabilities for radiology towards using truly virtual 3D images. It provides a more information to radiologists as compared to $2 \mathrm{D}$ images and maintains a vast amount of information due to its electronic storage capability. This technology is useful in radiology for the planning of different surgical approaches by guiding invasive procedures. ${ }^{[2,13]}$ It stores and retrieves $3 \mathrm{D}$ information which was a big challenge for traditional imaging technologies.

\section{Some Cases on Holography in the Medical Field}

Aarnisalo et al., 2009 performed a case to assess the position and thickness of a cartilage by using holography. ${ }^{[5]}$ Salvetti and Bertagni, 2016 used hologram to develop a medical test and devices used to monitor various conditions like infection, cardiac function and diabetes. This is used for advanced medical simulation and enables face-to-face training. It rapidly emerging in healthcare and makesthe education process more efficient and effective. ${ }^{[14]}$ Pathania et al., 2016 used holography for the proper assessment of lymphoma tissue. This is an essential technology to identify the cancer accurately in lesser time. ${ }^{[12]}$ Mishra, 2017 used holography for primitive designing in medical science. An organ hologram can be zoomed and edited in 3D space which makes the treatment and diagnosis processes more effective. In future, this technology can prevent uncomfortable physical procedures. ${ }^{[1]}$

\section{Holography Applications in the Medical Field}

Holography facilitates excellence in healthcare by sorting out complications in imaging. This technology can be 
useful to eliminate the requirements of physical testing procedure ${ }^{[15,16]}$ It easily stores digital $3 \mathrm{D}$ images of the patient or body parts. It employs reliable and efficient management of all records, and with better devices and improved storage facility, it is easy to analyse the progress. ${ }^{[17,18]}$ Holograms are available for various medical test and devices and are used to monitor diabetes, infections and check the proper functioning of soft and hard tissues. This technology is available to check drug, hormones, alcohol and glucose. ${ }^{[19,20]}$

Doctors can now use Colourful holography for proper monitoring and clinical trials and for studying complex images vascular, nervous and musculoskeletal systems. Now, doctors and surgeon can see the detailed images of soft and hard tissue of the human body. They can also see the human body from outside. Holography has the potential for a high level of achievement in medical research and development. Table 1 gives significant applications of holography in the medical field.

By using a holographic image, doctors can improve the quality of medical education and research. It used to reconstruct the image of tissue samples which helps to perform tissue surgeries. This technology is used for making the digital 3D prototype for neuroscience. This also offers help in the study of different orthopaedics structure. It is applicable to measure the strain on rods, pins and different bone fracture. Doctors can now see the anatomy of the patient without cutting into the body. ${ }^{[14,65]}$ It is useful to create technological advancement in the medical field.

\section{Discussion}

In the healthcare industry, the demand for medical holography is increasing for new treatment. The massive ability of this technology is to record and read data. Doctors and surgeon can enhance their communication with the patient to address the complex medical problem. It creates moving 3D images of body parts to create advancement in the imaging field. It helps doctors for proper diagnosis and treatment in a secure and timely manner. The applications of this technology are for medical imaging, urology, orthopaedics and medical institutions for research and development process. Medical images are visualised to create a hyper-realistic experience to empower the clinician. It helps measurements of internal cavities of the human body non-destructively. In dentistry, it is used to store tooth prints digitally. It quickly tests breath, saliva, blood and urine and provides a better understanding as compared to books/images. This technology provides a virtual environment, which helps to solve a complex issue.

However, it needs a large amount of storage space for better treatment of disease and injury. In orthopaedics, holography is an emerging tool to study and measure the external fracture of the bone. It allows seeing the structure of bone and their movement in real-time. These images help doctors for the treatment without the presence of the patient. Holography completely disrupts the way of communication of medical professionals. It avoids misunderstanding of a specific medical problem ensuring a better treatment. This digital holography is used to perform effective diagnosis and provide more clarity and patient satisfaction.

\section{Limitations and Future Scope}

It requires highly skilled human resources for capturing the 3D image. Most of the people are unfamiliar with this technology. Expensive hardware and software are required to produce and view the medical images. Holography imaging is costly as compared to $2 \mathrm{D}$ imaging. This technology is not successful during complex movements. The images captured by this technology are time-consuming and need specialised hardware and software. Export of datasets to create a hologram is a big concern.

In future, holography will provide 'Holodoctors' in the medical industry. It is possible that a doctor in a remote location can see the holography image and provide treatment. It will also be helpful for the manufacturing of pharmaceutical and healthcare products. In future, holography will provide an innovative solution for the development of healthcare. These 3D holographic images will also be helpful for business purposes. There is a need for medical persons to develop better applications of holography in their respective areas.

\section{Conclusion}

Holography has emerged as an innovative technology to record and display information in 3D format. The applications of this technology are in different fields of medical, engineering, science, graphics and arts. It plays a vital role in personalised medicine and healthcare facilitation. Holography image lowers the cost of planning and provides better outcomes for the patient. This technology is helpful for remote places in which the hologram of a patient is sent to the doctors by emails which can be examine for the status of the diseases without the physical presence of the patient. It is used for better planning of interventional procedures of structural heart diseases. A physician can manipulate a $3 \mathrm{D}$ heart structure in a holographic image. Thus, it can be used for better understanding of a patient's heart during the procedure.

Holography has good applications in ophthalmology, audiology, orthopaedics and dentistry. In medical science, holography is growing faster towards improving the understanding and better communications by which doctors can see the detailed structure of the patient. It provides a better understanding of multiple organs, anatomical structures and blood vessels. This technology is useful to 
Table 1: Major applications of holography in the medical field

Applications Description References

View of human With the help of holography, doctors can see accurate human skeletons, organs, muscle, veins and vessels skeletons It helps the surgeon for proper training and planning of the operation

Precisely shows complete skeleton with arteries plus nervous system and other aspects of the body

Stockmar et al., 2013 ${ }^{[21]} ;$ Zhang

et al., 2017 ${ }^{[22]}$; Yamada et al.,

Make effective representation of brain image and its intricate parts

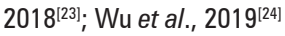

Helpful to improve the quality of treatment efficiently

Identification This technology enables to identify the abnormal growth of tissue, organs and even external body parts

of abnormal Researcher use holography to detect diseases and proper monitoring of health conditions like infections and

growth hormone imbalance

Helpful to researcher and doctors to eliminate the requirement of the physical testing procedure

Useful technology for proper representation of the abnormal 3D structure and other unwanted growth/fats

Used for the disease forecasting and identify advancement for the treatment procedure

Detect serious Used to detect a severe issue/abnormalities in tissues and organs in the human body

abnormalities The advancement of this technology is for various types of cells and Deoxyribonucleic Acid (DNA)

Provide multidimensional information by performing simultaneous imaging about abnormalities

Useful to carry out proper detection of disease, biomedical research \& analysis and other related applications

Inside map This technology allows the surgeon to see inside the patient body and facilitate the study of tissue structure

of the patient and other damages/growth

body Heart surgeon use hologram to see the children heart which can be helpful during the operations

Help Doctors carry dedicated procedures by employing a proper inside map with precision

Holography images are beneficial during surgery and are useful in comparing it with the previously captured image

Used to detect the blood loss during the surgery which can provide proper information to the surgeon

Inside fracture in bone and tissue can be analysed before the actual operation

Outside

mapping of

Doctors can see the external parts and other related details of the patient body and facilitate disease detection

patient body

and remote treatment

This technology is suitable to deliver effective teaching for imparting better medical education

Useful for detection of abnormality in body parts

Can eliminate some necessary physical testing

Presentation In medical education, this technology is suitable to deliver an effective presentation to students

and simulation It allows for a virtual lecture in real-time with the audience

Provide live simulation for better learning of the procedure

Proper presentation of the cardiovascular system and detect any heart defect at an early stage

Projected 3D holography digital image to precisely analyse the function and blood flow in the cardiovascular system

Emergency Provide better guidance during an emergency

care Helpful for proper treatment during accident situation with the help of previously-stored holography images

Bring new dimensions in modern communication system during emergency care

By using this technology, medical professionals can treat their patient remotely and in isolated areas

In a rural area, it improves access to the specialised consultant, and a patient may not have to visit the doctor physically at a far off place

Detailed heart For cardiologist, 3D holography image provides detailed information of patient heart as compared to $2 \mathrm{D}$ screen

information This modern visualisation technology provides a new opportunity to see the heart and its valves

Holography is used for proper scanning of body, medical checkup and sees the defective heart

It is a valuable tool which creates an immersive experience for crucial cardiac care and education

Provides endless possibilities in the area of cardiovascular diseases

Recording, In dentistry, useful to store the record of tooth prints and other dentistry models

storage and It checks the progress of the patient by storing all data digitally

retrieval of Provides nondestructive possibilities to see the gap and measurement of soft tissue with teeth

dental data Easily stored data of patient teeth digital and successfully carried out the study on these digital models in future

Original tooth prints are easily stored which can be used to check the accuracy of treatment

Ability to understand the complexity of treatment in the real world

Detailed Holography is used to provide precise information as a real visual field

colourful Researchers used this technology to view detailed and realistic colour organs

information of Reconstruct bright 3D image in natural colour which quickly provides solution of a given problem

the body and Used to make high resolution colourful digital medical model (recordkeeping)

its organs It is an important tool for human visual perception

Researcher use this technology to produce digital 3D images of museum displays and advertisement and animation

Breathe testing Holography used to create smart health by smartly indicating patient breathing problem

Useful for proper testing and monitoring of health and other medical conditions

Used to check environmental conditions to indicate, water quality and food to make effective health

Simpson et al., 2014 ${ }^{[25]}$;

Plascencia-Villa et al., 2016 ${ }^{[26] \text {; }}$

Rivenson et al., 2016 $6^{[27]}$

Moon and Javidi, 2007 ${ }^{[28]}$; Kjeldsen

et al., 2015 ${ }^{[29]}$; Ronzitti et al., 2017 $7^{[30]}$

Nesters et al., 2008 ${ }^{[31]}$; Dobrev et al., 2014 ${ }^{[32]}$; Rong et al., 2015[33]

Buzalewicz et al., 2016 ${ }^{[34]}$; Tahara et al., 2018 ${ }^{[35] ;}$ N Nobukawa et al., $2019^{[36]}$

Siegel et al., 2015 ${ }^{[37]}$; Brudfors et al., 2017 ${ }^{[38] ;}$ Bedrossian et al., 2017 ${ }^{[39]}$

Rodríguez et al., 2011 ${ }^{[40] ;}$; Jo et al., 2017 ${ }^{[41]}$; Krenkel et al., 2017 $7^{[42]}$

Song et al., 2016 ${ }^{[43]}$; Bocanegra et al., 2016 ${ }^{[44]}$; Merola et al., 2017 $7^{[45]}$

Also applied to monitor glucose level and proper analysis of human breathing

Galeotti et al., 2010 ${ }^{[52]}$; Makey et al.,

2019 ${ }^{[53]}$; Javaid and Haleem, 2019 [54] $^{\text {. }}$

Aarnisalo et al., 2010 [49]; Bishara et al., 2011 150]; De Angelis et al., 2019[51]

Furlong et al., 2013 ${ }^{[46]}$; Merrill et al., $2015^{[47]}$; Haleem and Javaid, 2019 ${ }^{[48]}$ 
Table 1: Contd...

\begin{tabular}{|c|c|c|}
\hline Applications & Description & References \\
\hline $\begin{array}{l}\text { Evaluating } \\
\text { patient } \\
\text { progress }\end{array}$ & $\begin{array}{l}\text { Doctors can now check the progress of the patient and can plan better planning for the treatment } \\
\text { Provide appropriate information about swelling during the injury of the patient } \\
\text { Used for successful treatment of many diseases by continuously check the progress } \\
\text { Doctors and surgeon not only see the medical image directly but also can rotate and slice } \\
\text { Better coordination between all health professionals without any risk of failure }\end{array}$ & $\begin{array}{l}\text { Rosen et al., 2006 } 6^{[55] ;} \text {; Flores-Moreno } \\
\text { et al., 2011 }{ }^{[56]} \text {; Haleem et al., } 2019^{[1]}\end{array}$ \\
\hline $\begin{array}{l}\text { Measurement } \\
\text { of body parts } \\
\text { and structure }\end{array}$ & $\begin{array}{l}\text { Holography is used for the precise measurement of human body structure } \\
\text { The best technique which enables to measure rough surface with high precision } \\
\text { Useful to determine the shape, size, length, diameter and orientation of the medical part } \\
\text { Used for inspection and testing of implants to maintain the quality } \\
\text { Proper measurement of the heart valve and another microfluidic channel } \\
\text { Detection of errors during the manufacturing of medical tools and devices } \\
\text { Also applicable to the measurement of toys and museum object }\end{array}$ & $\begin{array}{l}\text { Cheng et al., 2009[57]; Khaleghi et al., } \\
2013^{[58] ;} \text { Sobieranski et al., 2015 }{ }^{[59] ;} \\
\text { Shevkunov et al., 2019[60]; Haleem } \\
\text { et al., 2020[61] }\end{array}$ \\
\hline $\begin{array}{l}\text { Identify } \\
\text { complex } \\
\text { fractures }\end{array}$ & $\begin{array}{l}\text { Holography is precisely to identify and explain the complex fracture in human soft and hard tissue } \\
\text { It analyses the fracture during the peak load of the human body and its process of causes } \\
\text { Helps to detect the problems in the ongoing situation of the complex disease } \\
\text { This technology is helpful to perform complex surgery precisely and betterment of meditational lesions }\end{array}$ & $\begin{array}{l}\text { Cantu-Valle et al., 2014 } \\
\text { Sapozhnikov et al., } 2015^{[19]} ; \text { Tahara } \\
\text { et al., 2018 }\end{array}$ \\
\hline $\begin{array}{l}\text { Medical } \\
\text { educations }\end{array}$ & $\begin{array}{l}\text { This technology is important in medical colleges for the design and development of artificial bones, joints and } \\
\text { prosthetic limbs } \\
\text { The applications of this technology facilitate the research and development in the medical field } \\
\text { The best tool for the teaching and learning of the medical student in the real world } \\
\text { Students can precisely learn about the cause of diseases and their effects } \\
\text { In future, it will successfully be used in medical education, teaching, learning and biomedical research }\end{array}$ & $\begin{array}{l}\text { Ozsoy-Keskinbora et al., 2014 }{ }^{[64]} \text {; } \\
\text { Nobukawa et al., 2019 }\end{array}$ \\
\hline
\end{tabular}

develop 3D hologram of various cells, organs and tissue, which can further be studied from various angles. It is helpful to research and study the effects of various drugs on the individual patient. It improves the understanding of the complex anatomy of the individual patient and can also provide better information regarding chronic kidney disease. This technology seems to be a better teaching tool as compared to other conventional imaging tools.

\section{Financial support and sponsorship}

Nil.

\section{Conflicts of interest}

There are no conflicts of interest.

\section{References}

1. Mishra S. Hologram the future of medicine - From Star Wars to clinical imaging. Indian Heart J2017;69:566-7.

2. Haleem A, Javaid M, Vaishya R. Holography applications for orthopaedics. Indian J Radiol Imaging 2019;29:477-9.

3. Kreider W, Yuldashev PV, Sapozhnikov OA, Farr N, Partanen A, Bailey MR, et al. Characterization of a multi-element clinical HIFU system using acoustic holography and nonlinear modeling. IEEE Trans Ultrason Ferroelectr Freq Control 2013;60:1683-98.

4. Khaleghi M, Guignard J, Furlong C, Rosowski JJ. Simultaneous full-field 3-D vibrometry of the human eardrum using spatial-bandwidth multiplexed holography. J Biomed Opt 2015;20:111202. doi: 10.1117/1.JBO.20.11.111202.

5. Aarnisalo AA, Cheng JT, Ravicz ME, Hulli N, Harrington EJ, Hernandez-Montes MS, et al. Middle ear mechanics of cartilage tympanoplasty evaluated by laser holography and vibrometry. Otol Neurotol 2009;30:1209-14.

6. Mudanyali O, Tseng D, Oh C, Isikman SO, Sencan I, Bishara W, et al. Compact, light-weight and cost-effective microscope based on lensless incoherent holography for telemedicine applications. Lab Chip 2010;10:1417-28.
7. Haleem A, Javaid M, Vaishya, R. Industry 4.0 and its applications in orthopaedics. J Clin Orthop Trauma 2019:10:615-6.

8. Wei Q, McLeod E, Qi H, Wan Z, Sun R, Ozcan A. On-chip cytometry using plasmonic nanoparticle enhanced lens-free holography. Sci Rep 2013;3:1699. doi: 10.1038/srep01699.

9. Khaleghi M, Furlong C, Ravicz M, Cheng JT, Rosowski JJ. Three-dimensional vibrometry of the human eardrum with stroboscopic lensless digital holography. J Biomed Opt 2015;20:051028. doi: 10.1117/1.JBO.20.5.051028.

10. Wang Y, Yang Y, Wang D, Ouyang L, Zhang Y, Zhao J, et al. Morphological measurement of living cells in methanol with digital holographic microscopy.Comput Math Methods Med 2013;2013:715843. doi: 10.1155/2013/715843.

11. Liu CH, Schill A, Raghunathan R, Wu C, Singh M, Han Z, et al. Ultra-fast line-field low coherence holographic elastography using spatial phase shifting. Biomed Opt Express 2017;8:993-1004.

12. Pathania D, Im H, Kilcoyne A, Sohani AR, Fexon L, Pivovarov M, et al. Holographic assessment of lymphoma tissue (HALT) for global oncology field applications. Theranostics 2016;6:1603-10.

13. Bernhardt M, Nicolas JD, Osterhoff M, Mittelstädt H, Reuss M, Harke B, et al. Correlative microscopy approach for biology using X-ray holography, X-ray scanning diffraction and STED microscopy. Nat Commun 2018;9:3641. doi: 10.1038/ s41467-018-05885-z.

14. Salvetti F, Bertagni B. Interactive holograms and tutorials in healthcare education: Case studies from the e-REAL experience. Int J Adv Corporate Learn 2016;9. doi: 10.3991/ijac.v9i2.5988.

15. Burgner J, Simpson AL, Fitzpatrick JM, Lathrop RA, Herrell SD, Miga MI, et al. A study on the theoretical and practical accuracy of conoscopic holography-based surface measurements: Toward image registration in minimally invasive surgery. Int J Med Robot 2013;9:190-203

16. Prozorov T, Almeida TP, Kovács A, Dunin-Borkowski RE. Off-axis electron holography of bacterial cells and magnetic nanoparticles in liquid. J R Soc Interface 2017;14. pii: 20170464. doi: 10.1098/rsif. 2017.0464.

17. Isikman SO, Bishara W, Mudanyali O, Sencan I, Su TW, Tseng D, et al. Lensfree on-chip microscopy and tomography for bio-medical applications. IEEE J Sel Top Quantum Electron 2011;18:1059-72. 
18. Lin WT, Lin CY, Singh VR, Luo Y. Speckle illumination holographic non-scanning fluorescence endoscopy. J Biophotonics 2018;11:e201800010. doi: 10.1002/jbio.201800010.

19. Sapozhnikov OA, Tsysar SA, Khokhlova VA, Kreider W. Acoustic holography as a metrological tool for characterizing medical ultrasound sources and fields. J Acoust Soc Am 2015;138:1515-32.

20. Guillon M, Forget BC, Foust AJ, De Sars V, Ritsch-Marte M, Emiliani V. Vortex-free phase profiles for uniform patterning with computer-generated holography. Opt Express 2017;25:12640-52.

21. Stockmar M, Cloetens P, Zanette I, Enders B, Dierolf M, Pfeiffer F, et al. Near-field ptychography: Phase retrieval for inline holography using a structured illumination. Sci Rep 2013;3:1927. doi: 10.1038/ srep01927.

22. Zhang J, Sun J, Chen Q, Li J, Zuo C. Adaptive pixel-super-resolved lensfree in-line digital holography for wide-field on-chip microscopy. Sci Rep 2017;7:11777. doi: 10.1038/s41598-017-11715-x.

23. Yamada $S$, Kakue T, Shimobaba T, Ito T. Interactive holographic display based on finger gestures. Sci Rep 2018;8:2010. doi: 10.1038/ s41598-018-20454-6.

24. Wu Y, Luo Y, Chaudhari G, Rivenson Y, Calis A, de Haan K, et al. Bright-field holography: Cross-modality deep learning enables snapshot 3D imaging with bright-field contrast using a single hologram. Light Sci Appl 2019;8:25. doi: 10.1038/s41377-019-0139-9.

25. Simpson AL, Sun K, Pheiffer TS, Rucker DC, Sills AK, Thompson RC, et al. Evaluation of conoscopic holography for estimating tumor resection cavities in model-based image-guided neurosurgery. IEEE Trans Biomed Eng 2014;61:1833-43.

26. Plascencia-Villa G, Ponce A, Collingwood JF, Arellano-Jiménez MJ, Zhu X, Rogers JT, et al. High-resolution analytical imaging and electron holography of magnetite particles in amyloid cores of Alzheimer's disease. Sci Rep 2016;6:24873. doi: 10.1038/srep24873.

27. Rivenson $\mathrm{Y}, \mathrm{Wu} \mathrm{Y}$, Wang H, Zhang Y, Feizi A, Ozcan A. Sparsity-based multi-height phase recovery in holographic microscopy. Sci Rep 2016;6:37862. doi: 10.1038/srep37862.

28. Moon I, Javidi B. Three-dimensional identification of stem cells by computational holographic imaging. J R Soc Interface 2007;4:305-13.

29. Kjeldsen HD, Kaiser M, Whittington MA. Near-field electromagnetic holography for high-resolution analysis of network interactions in neuronal tissue. J Neurosci Methods 2015;253:1-9.

30. Ronzitti E, Conti R, Zampini V, Tanese D, Foust AJ, Klapoetke N, et al. Submillisecond optogenetic control of neuronal firing with two-photon holographic photoactivation of chronos. J Neurosci 2017;37:10679-89.

31. Nesterets Y, Gureyev T, Stevenson A, Pogany A, Wilkins S, Kincaid $\mathrm{R}$, et al. Soft tissue small avascular tumor imaging with x-ray phase-contrast micro-CT in-line holography. Proc SPIE Int Soc Opt Eng 2008;6913:69133z. doi: 10.1117/12.772761.

32. Dobrev I, Furlong C, Cheng JT, Rosowski JJ. Full-field transient vibrometry of the human tympanic membrane by local phase correlation and high-speed holography. J Biomed Opt 2014;19:96001.

33. Rong L, Latychevskaia T, Chen C, Wang D, Yu Z, Zhou X, et al. Terahertz in-line digital holography of human hepatocellular carcinoma tissue. Sci Rep 2015;5:8445. doi: 10.1038/srep08445.

34. Buzalewicz I, Kujawińska M, Krauze W, Podbielska H. Novel perspectives on the characterization of species-dependent optical signatures of bacterial colonies by digital holography.PLoS One 2016;11:e0150449. doi: 10.1371/journal.pone.0150449.

35. Tahara T, Quan X, Otani R, Takaki Y, Matoba O. Digital holography and its multidimensional imaging applications: A review. Microscopy (Oxf) 2018;67:55-67.

36. Nobukawa T, Katano Y, Muroi T, Kinoshita N, Ishii N. Bimodal incoherent digital holography for both three-dimensional imaging and quasi-infinite-depth-of-field imaging. Sci Rep 2019;9:3363. doi:

\subsection{8/s41598-019-39728-8}

37. Siegel N, Storrie B, Bruce M, Brooker G. CINCH (confocal incoherent correlation holography) super resolution fluorescence microscopy based upon FINCH (Fresnel incoherent correlation holography). Proc SPIE Int Soc Opt Eng 2015;9336:93360S. doi: 10.1117/12.2081319.

38. Brudfors M, García-Vázquez V, Sesé-Lucio B, Marinetto E, Desco M, Pascau J. ConoSurf: Open-source 3D scanning system based on a conoscopic holography device for acquiring surgical surfaces. Int J Med Robot 2017;13:e1788. doi: 10.1002/rcs.1788

39. Bedrossian M, Barr C, Lindensmith CA, Nealson K, Nadeau JL. Quantifying microorganisms at low concentrations using digital holographic microscopy (DHM). J Vis Exp 2017;:e56343. doi: $10.3791 / 56343$.

40. Rodríguez GL, Weber J, Sandhu JS, Anastasio MA. Feasibility study of complex wavefield retrieval in off-axis acoustic holography employing an acousto-optic sensor. Ultrasonics 2011;51:847-52.

41. Jo Y, Park S, Jung J, Yoon J, Joo H, Kim MH, et al. Holographic deep learning for rapid optical screening of anthrax spores.Sci Adv 2017;3:e1700606. doi: 10.1126/sciadv.1700606.

42. Krenkel M, Toepperwien M, Alves F, Salditt T. Three-dimensional single-cell imaging with $\mathrm{X}$-ray waveguides in the holographic regime. Acta Crystallogr A Found Adv 2017;73:282-92.

43. Song J, Leon Swisher C, Im H, Jeong S, Pathania D, Iwamoto Y, et al. Sparsity-based pixel super resolution for lens-free digital in-line holography. Sci Rep 2016;6:24681. doi: 10.1038/srep24681.

44. Bocanegra Evans H, Gorumlu S, Aksak B, Castillo L, Sheng J. Holographic microscopy and microfluidics platform for measuring wall stress and 3D flow over surfaces textured by micro-pillars. Sci Rep 2016;6:28753. doi: 10.1038/srep28753.

45. Merola F, Memmolo P, Miccio L, Savoia R, Mugnano M, Fontana A, et al. Tomographic flow cytometry by digital holography.Light Sci Appl 2017;6:e16241. doi: 10.1038/lsa.2016.241.

46. Furlong C, Dobrev I, Rosowski J, Cheng J. Assessing eardrum deformation by digital holography. SPIE Newsroom 2013. doi 10.1117/2.1201212.004612.

47. Merrill D, An R, Turek J, Nolte DD. Digital holography of intracellular dynamics to probe tissue physiology. Appl Opt 2015;54:89-97.

48. Haleem A, Javaid M. Additive manufacturing applications in Industry 4.0: A review. J Indus Integration Manag 2019. doi: 10.1142/S2424862219300011.

49. Aarnisalo AA, Cheng JT, Ravicz ME, Furlong C, Merchant SN, Rosowski JJ. Motion of the tympanic membrane after cartilage tympanoplasty determined by stroboscopic holography. Hear Res 2010;263:78-84.

50. Bishara W, Sikora U, Mudanyali O, Su TW, Yaglidere O, Luckhart $\mathrm{S}$, et al. Holographic pixel super-resolution in portable lensless on-chip microscopy using a fibre-optic array. Lab Chip 2011;11:1276-9.

51. De Angelis A, Ferrara MA, Coppola G, Di Matteo L, Siani L, Dale B, et al. Combined Raman and polarization sensitive holographic imaging for a multimodal label-free assessment of human sperm function. Sci Rep 2019;9:4823. doi: 10.1038/s41598-019-41400-0.

52. Galeotti JM, Siegel M, Stetten G. Real-time tomographic holography for augmented reality. Opt Lett 2010;35:2352-4.

53. Makey G, Yavuz Ö, Kesim DK, Turnalı A, Elahi P, Ilday S, et al. Breaking crosstalk limits to dynamic holography using orthogonality of high-dimensional random vectors. Nat Photonics 2019;13:251-6.

54. Javaid M, Haleem, A. Industry 4.0 applications in medical field: A brief review. Curr Med Res Pract 2019;9:102-9.

55. Rosen J, Indebetouw G, Brooker G. Homodyne scanning holography. Opt Express 2006;14:4280-5. 
56. Flores-Moreno JM, Furlong C, Rosowski JJ, Harrington E, Cheng JT, Scarpino C, et al. Holographic otoscope for nano displacement measurements of surfaces under dynamic excitation. Scanning 2011;33:342-52.

57. Cheng JT, Aarnisalo AA, Harrington E, Hernandez-Montes Model S, Furlong C, Merchant SN, et al. Motion of the surface of the human tympanic membrane measured with stroboscopic holography. Hear Res 2010;263:66-77.

58. Khaleghi M, Lu W, Dobrev I, Cheng JT, Furlong C, Rosowski JJ. Digital holographic measurements of shape and 3D sound-induced displacements of Tympanic Membrane. Opt Eng 2013;52:101916. doi: 10.1117/1.OE.52.10.101916.

59. Sobieranski AC, Inci F, Tekin HC, Yuksekkaya M, Comunello E, Cobra D, et al. Portable lensless wide-field microscopy imaging platform based on digital inline holography and multi-frame pixel super-resolution. Light Sci Appl 2015;4:e346. doi: 10.1038/ lsa.2015.119.

60. Shevkunov I, Katkovnik V, Claus D, Pedrini G, Petrov NV, Egiazarian K. Spectral object recognition in hyperspectral holography with complex-domain denoising. Sensors (Basel) 2019;19:5188. doi: 10.3390/s19235188.
61. Haleem A, Javaid M, Khan IH. Current status and applications of Artificial Intelligence (AI) in medical field: An overview. Curr Med Res Pract 2020;9:231-7.

62. Cantu-Valle J, Ruiz-Zepeda F, Mendoza-Santoyo F, Jose-Yacaman M, Ponce A. Calibration for medium resolution off-axis electron holography using a flexible dual-lens imaging system in a JEOL ARM 200F microscope.Ultramicroscopy 2014;147:44-50. doi: 10.1016/j.ultramic.2014.06.003. Epub 2014 Jun 30. PMID: 25016585; PMCID: PMC4307790.

63. Haleem A, Javaid M, Khan MI. Artificial intelligence (AI) applications in dentistry. Curr Med Res Pract 2019. doi: 10.1016/j. cmrp.2019.12.002.

64. Ozsoy-Keskinbora C, Boothroyd CB, Dunin-Borkowski RE, van Aken PA, Koch CT. Hybridization approach to in-line and off-axis (electron) holography for superior resolution and phase sensitivity.Sci Rep 2014;4:7020. doi: 10.1038/srep07020. PMID: 25387480; PMCID: PMC4228327.

65. Ryu D, Wang Z, He K, Zheng G, Horstmeyer R, Cossairt O. Subsampled phase retrieval for temporal resolution enhancement in lensless on-chip holographic video. Biomed Opt Express 2017;8:1981-95. 